\title{
MISCELANEA
}

\section{CALIDAD DEL AGUA POTABLE EN HUESCA}

QUALITY OF THE DRINKABLE WATER IN HUESCA

\author{
Autores \\ Sancho Arroyo Sandra* \\ Pablo Aranda, Miriam** \\ * Estudiante de $3^{\circ}$ Enfermería. Universidad de Zaragoza \\ ** Miriam Pablo Aranda, diplomada en enfermería. Universidad de Zaragoza
}

Palabras clave: calidad, agua potable, Huesca

Keywords: quality, dinckable water, Huesca

\section{RESUMEN}

El agua es uno de los recursos naturales fundamentales; es, seguramente el recurso que condiciona de manera prioritaria el desarrollo socioeconómico de los pueblos y la mejora del bienestar de la población. El agua presta un extraordinario servicio a la comunidad para mejorar su calidad de vida, pero, sobre todo, para satisfacer sus necesidades básicas, tales como la alimentación y la salud. Sin agua no son posibles las actividades agropecuarias y, especialmente, las agrícolas, que son el mayor componente de la alimentación de la humanidad. La salud de la población ha mejorado cuando ésta ha podido vivir en un ambiente sano y con unas prácticas higiénicas, gracias al empleo suficiente de agua potable. El saneamiento de las aguas y la posibilidad de hacer un uso continuo de ellas, ha contribuido además, al crecimiento demográfico. [1]

El agua es tanto un derecho como una responsabilidad. Tiene un valor económico, social y ambiental, cualquier actuación pública y privada está obligada a tener en cuenta esta triple dimensión. Sin olvidar el valor decorativo y simbólico: en el jardín islámico, el agua tiene un valor sensual, en el jardín oriental acentúa su valor religioso y en la religión cristiana es símbolo de purificación, todo ello expresado a través de fuentes, cascadas, riachuelos... No es un bien ilimitado, ni su disponibilidad en cuantía y calidad adecuada es gratuita. Hay que tener en cuenta tanto los costes reales como el beneficio económico que genera su utilización, respetando al mismo tiempo la exigencia de un caudal mínimo para mantener los ecosistemas.[2]

\section{ABSTRACT}

Water is a fundamental natural resource, and surely the resource that conditions the social-economic 
development of people and improves the welfare of the population. Water provides an extraordinary service to the community to improve their quality of life, but above all, to meet their basic needs such as food and health. Without water, farming activities are not possible and especially agricultural ones, which are the largest component of the power of humanity. The health of the population has improved when it has been able to live in healthy and hygienic practices, through the use of sufficient water. The restoration of water and the possibility of a continued use, has contributed also to increase the global population.

Water is both a right and a responsibility. It has an economic, social and environmental value; all public and private action is required to take account of this triple dimension. Not to mention the decorative and symbolic value in the Islamic garden, where the water is a sensual value, whereas in the oriental garden emphasizes its religious and value and in the Christian religion is considered a symbol of purification, all expressed through fountains, waterfalls, streams ... Neither it is not a unlimited good, nor their availability in adequate quantity and quality is free. We must take into account both the actual costs as the economic benefit from their use, by respecting the requirement of a minimum flow to maintain ecosystems.

\section{INTRODUCCIÓN}

Algo tan sencillo para nosotros como abrir el grifo y que salga por él agua limpia y apta para el consumo no es tarea sencilla, el agua es un producto manufacturado de elevados costes [3]. De hecho, hoy en día hay 1.400 millones de personas que carecen de agua potable en el mundo, según datos de la ONU. Disponer de agua potable de calidad y en cantidad suficiente es una necesidad para nuestro adecuado desarrollo y también lo es un uso solidario y eficiente de este bien escaso.

El agua es fuente de vida pero también es el medio de transmisión de muchas de las enfermedades más virulentas que han azotado a la humanidad. En ella viven y se multiplican multitud de microorganismos, la mayoría de los

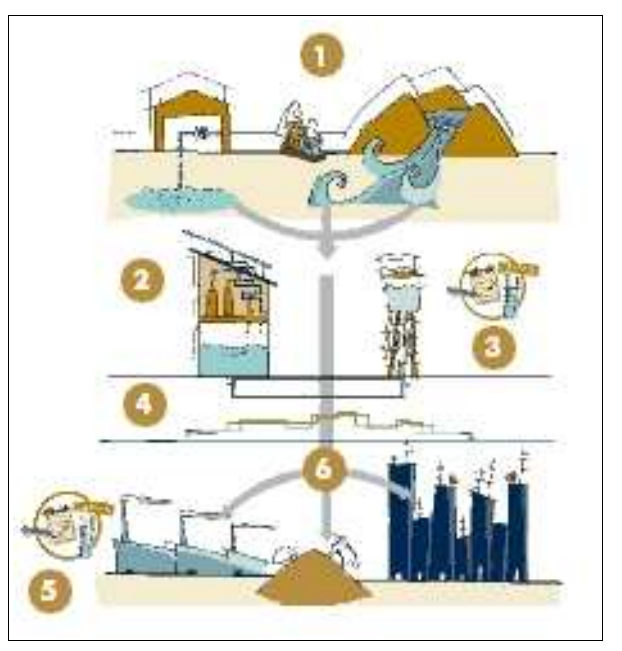
cuales son inocuos pero algunos pueden transmitir a los humanos trastornos en su salud y ocasionar graves epidemias. Se dice que las enfermedades de origen hídrico han ocasionado a lo largo de la historia más muertes que todas las guerras juntas. Aún hoy en día, el consumo de agua sin potabilizar es la causa de la muerte de más de tres millones de personas cada año y del $80 \%$ de las enfermedades que afectan a la humanidad.[4]

El abastecimiento de agua para su uso doméstico comprende una serie de fases:

A) La captación es el origen del abastecimiento. El agua bruta puede provenir de aguas superficiales (ríos, lagos, embalses, canales...) o de aguas subterráneas (pozos, manantiales, surgencias). Cuanta mayor calidad tenga, menores serán los tratamientos de potabilización a los que habrá que someterla. En ocasiones se construyen depósitos de reserva de agua bruta, que aseguran el suministro durante un cierto tiempo en caso de cortes de la fuente de abastecimiento.

B) Potabilización, se realiza en la planta potabilizadora, es el conjunto de tratamientos que permiten que el agua sea apta para el consumo humano y pueda beberse con garantía de calidad. Según la calidad del agua bruta se precisan diversos procesos para conseguir que el agua sea potable, entre ellos destacan: desbaste/tamizado que consiste en hacer pasar el agua captada por unas rejas para retener los materiales de gran tamaño que van por el agua. Coagulación y floculación, la adición de sustancias como sulfato de alúmina o poli electrolitos permite que 
partículas con idéntica carga eléctrica, que de manera natural se repelen y no sedimentan, se desestabilicen, coagulen y formen flóculos capaces de sedimentar. También está la decantación, consiste en separar por gravedad las partículas en suspensión que transporta el agua consiguiendo un flujo de agua con la menor turbulencia posible, de manera que las partículas más densas decantan y sedimentan en el fondo. Las menos densas flotan y van a parar a la superficie, donde se eliminan. Filtración, las aguas previamente decantadas se hacen pasar por un medio poroso, quedando retenidas partículas sólidas en suspensión de diferentes tamaños en función de las características del filtro. En general, no consiguen eliminar elementos disueltos como los contaminantes químicos, pero sí muchas sustancias que le dan turbidez al agua, incluso huevos de parásitos. Los filtros más utilizados son los de arena y los de carbón activado, estos últimos, además, pueden eliminar diversos contaminantes por un proceso químico llamado adsorción. Pueden ser filtros abiertos, que filtran por gravedad, o filtros cerrados, a presión. [5] La desinfección es la más importante, ya que garantiza la eliminación de los microorganismos presentes en el agua que pueden causar gran número de enfermedades. Existen diversos métodos físicos (calor) y químicos (cloro, ozono, sales metálicas) para desinfectar el agua, pero el más utilizado en abastecimiento es la cloración, ya que es barato, sencillo, eficaz, tiene acción residual y fácil determinación. El sistema más utilizado en pequeños núcleos es la cloración mediante hipoclorito sódico (liquido) o hipoclorito cálcico (en pastillas o granulado).

Una vez potabilizada hay que almacenarla, el almacenamiento del agua ya tratada debe realizarse en depósitos protegidos, bien conservados y limpios. Con frecuencia, se construyen depósitos elevados para asegurar la distribución por gravedad desde el depósito de almacenamiento de agua tratada. Una ves lista para su consumo, el agua tiene diversos usos: domésticos, industriales, públicos...

C) Vigilancia y control que realizan análisis químicos y biológicos de diversos parámetros del agua para asegurar su calidad y potabilidad tanto a la salida de la planta como en diversos puntos de la red de abastecimiento, según sistemática municipal.

Hemos tomado como ejemplo el caso de la ciudad de Huesca. Del siglo XVI al siglo XIX, el uso y consumo de la nieve y del hielo fue una actividad importante y de gran beneficio económico. En Huesca, la gran demanda de este producto llevó consigo la construcción de numerosas neveras o pozos de nieve, tanto en la montaña como en la tierra baja. Se pueden diferenciar: las neveras de "abastecimiento", se sitúan en las montañas, en ellas se recogía la nieve y se guardaba en pozos, en capas de unos $50 \mathrm{~cm}$. de grosor, separadas entre sí con paja; y las neveras de "producción" construidas en los cascos urbanos, su función era guardar la nieve bajada de los pozos de montaña, producir hielo y conservarlo para su posterior consumo.

La ciudad de Huesca disponía de varios pozos repartidos en las sierras situadas al norte de la capital: sierra de Guara, Sierra de Sevil y zona de Rodellar; que servían de abastecimiento al Hospital Provincial y al centro.

En la provincia, se conocen documentos del abastecimiento de Monzón con producto traído de los pozos de Benabarre, Calasanz, Fonz, Camporrells, etc. La tierra baja de la provincia disponía de varios pozos en distintas poblaciones, distribuidos de forma que cubrían el abastecimiento en el sur de la provincia.[6]

Poco a poco el sistema de abastecimiento de agua en Huesca capital se fue quedando obsoleto y uno de los objetivos prioritarios fue la modernización de todo el sistema. Ya en los inicios del siglo XX se invirtió en la modernización y construcción de nuevas infraestructuras de la red de almacenamiento y distribución de agua potable. La intervención fue rápida, se ejecutaron obras que permitieron dotar a Huesca de un abastecimiento alternativo, procedente del Canal del Cinca y 
evitar las restricciones durante el verano.

Si la ciudad de Huesca a finales del siglo XIX tenía 12.626 habitantes, a finales del siglo XX contaba con 37.610 habitantes, crecimiento lento pero sostenido que se mantiene hasta nuestros días. Ya en el siglo XXI, el Ministerio de Medio Ambiente aprobó un proyecto para impulsar los trabajos iniciados por la Dirección General de Aragón en el Proyecto de Conducción de Agua Potable a la Ciudad de Huesca. De estos trabajos, se derivó un estudio integral sobre el sistema de abastecimiento a la ciudad de Huesca y su entorno desde las distintas fuentes de suministro (Vadiello, Monrepós y Cinca).

El Congreso de los Diputados instó al Gobierno de la Nación a impulsar la cooperación Institucional para acometer todas las actuaciones que se deriven del citado estudio en materia de almacenamiento, conducción, potabilización y distribución del agua en la ciudad de Huesca y su entorno, dado que la inversión necesaria es elevada. [7]

En la actualidad las infraestructuras de captación y regulación para la ciudad de Huesca son las siguientes: 1. Embalse de Vadiello (río Guatizalema): el agua es llevada por la conducción de Vadiello a los depósitos de Loporzano y Montearagón. 2. Pozos de la Almunia: para complemento de la concesión utilizada de Vadiello, pendientes de equipamiento. 3.-Embalse de Santa María de Belsué y Cienfuens (río Flumen): a través de la acequia de Tierz. Nunca superan los $6 \mathrm{Hm} 3$ embalsados debido a las filtraciones (PH Ebro). 4.-Embalse de Valdabra (barranco de Valdabra): conectado a la red de abastecimiento de Huesca como emergencia en la sequía 2004/05. Mediante el canal del Cinca y bombeo. 5-.Embalse de Montearagón: pendiente puesta en marcha. Actualmente en fase de carga. 6.-Toma manantial de San Julián de Banzo. 7.-Toma manantial de Fuenmayor, afloramiento de acuíferos cársticos de la UH Sierra de Guara. Recarga por filtraciones de embalses Flumen. 8.-Tomas para suministros menores: Manantial de las Paulesas, aguas subterráneas de Huesca. [8]

La potabilizadora de Huesca sigue el modelo actual de fangos activos, digestión anaerobia, filtración y desinfección. Para la desinfección se utiliza hipoclorito sódico. El cloro es el desinfectante del agua más utilizado en el mundo por su efectividad, su bajo coste y fácil uso. Según la Organización Mundial de la Salud, "En la actualidad, la desinfección con cloro es la mejor garantía del agua microbiológicamente potable". Por sus propiedades, el cloro es efectivo para combatir todo tipo de microbios contenidos en el agua incluidos bacterias, virus, hongos y levaduras y las algas y limos que proliferan en el interior de las tuberías de suministro y en los depósitos de almacenamiento. [9] Si bien, hay voces que cuestionan su uso asociándolo con los cánceres de vejiga, es la opción menos mala por no tener otra mejor [10]

En cuanto al sistema de control de suministro de agua de Huesca se basa en la instalación de una serie de autómatas y modems GPRS (General Packet Radio System) a lo largo de puntos significativos de la conducción hasta la ciudad. Estos autómatas controlan los elementos hidráulicos (bombas, válvulas, etc.) y los sensores a medida para la obtención de datos. La información de los autómatas se centraliza en un servidor municipal diseñado e instalado a tal efecto. Las transmisiones entre autómatas y el servidor se realizan vía GPRS, consiguiendo una disminución del coste respecto a sistemas GSM (Global System for Mobile Communications). Accediendo a dicho servidor se pueden realizar las operaciones de telecontrol (maniobra de componentes), análisis de datos históricos y análisis de suministro en tiempo real.

Para el control de calidad de aguas de consumo humano en Huesca, con fecha Mayo del 2004 el Ayuntamiento de Huesca contrata con Gestión de Aguas de Aragón, empresa perteneciente al grupo AGBAR, Aguas de Barcelona (empresa privada), con presencia en más de ochenta municipios. En treinta de ellos realiza la gestión integral del abastecimiento y en el resto se dedica a adaptar el control de la calidad de agua de consumo en esta Comunidad Autónoma.

Gestión de Aguas de Aragón en colaboración con el Personal Técnico Municipal y de acuerdo con 
la Subdirección Provincial de Salud Pública de Huesca han elaborado el Plan de Autocontrol que incrementa las exigencias tanto del RD 140/2003 como del Programa de Vigilancia Sanitaria de la Comunidad de Aragón que especifica los puntos de muestreo:

A) Tratamiento: Loporzano, Vadiello y Paulesas,

B) Depósitos de distribución: I.E.S (Instituto de Educación Secundaria).-E.U.P.H (Escuela Universitaria Politécnica de Huesca) y SEPES (Entidad Pública Empresarial de Suelo)

C) Red de distribución: Plaza Lérida, Plaza Santo Domingo, Avda. Martínez de Velasco, Plaza Concepción Arenal y Bellestar del Flumen.

La frecuencia de muestreo depende del tipo de análisis que se quiere realizar:

A) Muestreo diario: nivel de cloro y $\mathrm{pH}$,

B) Dos veces por semana: examen organoléptico que consiste en la valoración de las características organolépticas del agua de consumo humano en base al olor, sabor, color y turbidez.

C) Cada 6 días: análisis de control y completos, este tipo de análisis tiene por objeto facilitar la información sobre la calidad organoléptica y microbiológica del agua de consumo humano así como información sobre la eficacia del tratamiento, y si el agua de consumo humano distribuida respeta los valores paramétricos contenidos en el Real Decreto.

D) Tres veces al mes: Análisis Grifo del consumidor y análisis complementarios que facilitan las características organolépticas y microbiológicas e informa sobre la eficacia del tratamiento

En el plano 1 se ven las estaciones donde se controlan diversos parámetros [11]

- Estación barranco de la Alfondida.

- Estación Depósito del Seminario.

- Estación Depósito de Cola.

- Estación Depósito SEPES.

En cuanto a los usos, el abastecimiento de población o demanda urbana incluye los servicios de agua a los usuarios domésticos, industriales, institucionales y de servicios conectados a la red de distribución municipal"

\section{CONCLUSIÓN}

Hoy en día se puede decir, en lo que se refiere a Huesca, que gracias a la cooperación existente entre el Ayuntamiento de Huesca, el Instituto Aragonés del Agua del Gobierno de Aragón y el Ministerio de Medio Ambiente se han modernizado instalaciones y se han construido otras nuevas que permitirán a los oscenses disfrutar de agua potable de calidad, sin problemas de abastecimiento. [12]

Y como conclusión final, se puede afirmar con rotundidad que el agua es esencial para la vida. Nuestra existencia, así como las actividades económicas dependen totalmente de este precioso recurso. De hecho, los recursos hidráulicos se ven afectados por múltiples usos como son los de la agricultura, la industria y el consumo doméstico. El agua, por lo tanto, es la garantía de nuestro desarrollo y de nuestro futuro, porque es el elemento que permite el asentamiento de la población y la mejora de sus condiciones de vida. Por todo ello son importantes y muy necesarias las actuaciones en materia de agua. 


\section{PLANO 1}

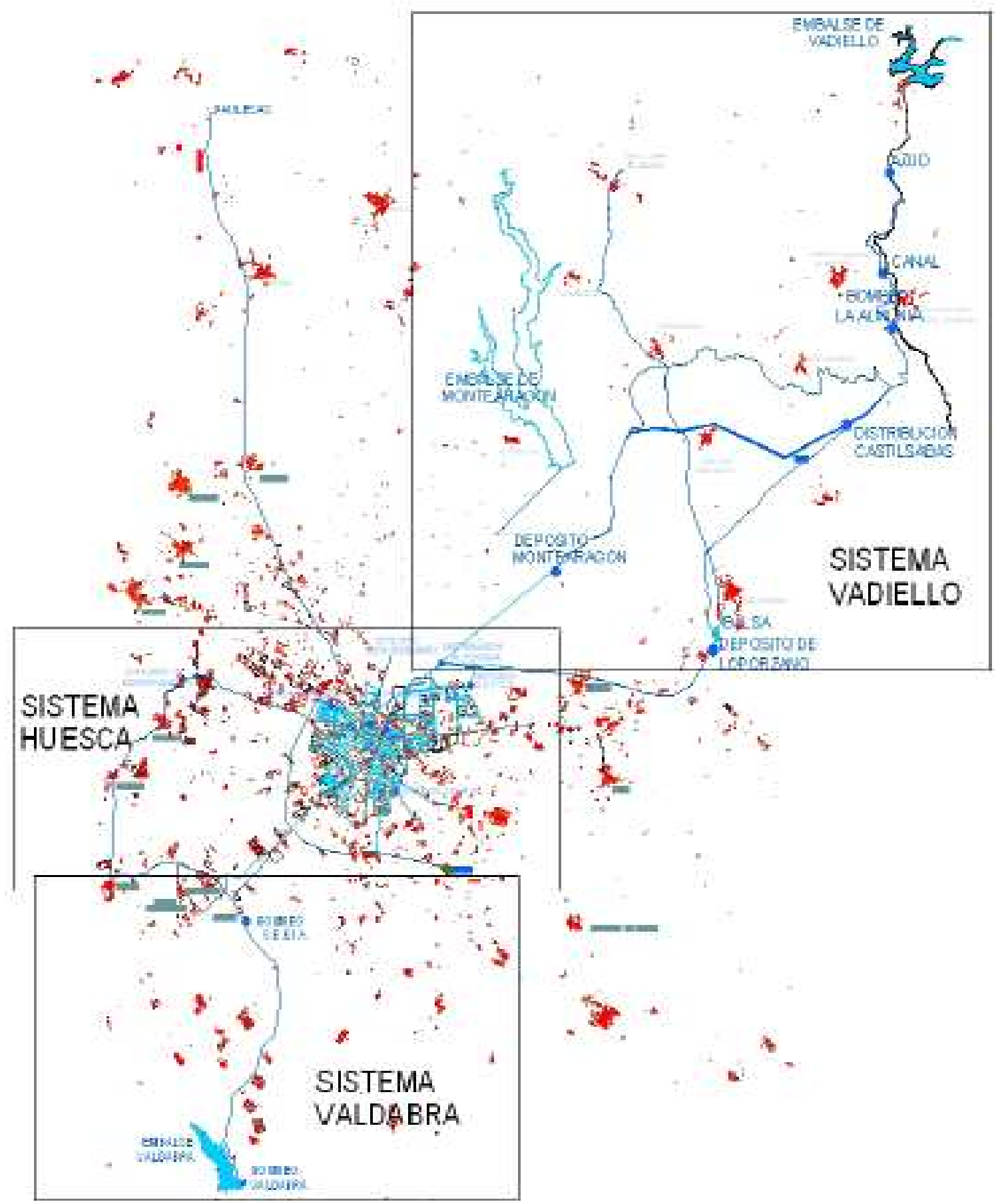




\section{BIBLIOGRAFÍA}

[1] Indicadores de Salud: $4^{\mathrm{a}}$ evaluación en España del programa regional Europeo Salud para todos. Ministerio de Sanidad y Consumo; 1999. p. 255.

[2] http://www.ine.es/revistas/cifraine/0108.pdf

[3] Coste de potabilización, de consumo que pagamos en parte cada familia/casa, pero su mayor porcentaje corre a cargo de los ayuntamientos.

[4] www.eurochlor.org/upload/documents/document194.pdf. Asociación Nacional de Elctroquímica.

[5] http://portal.aragon.es/portal/page/portal/IAA/ABASTECIMIENTO/POTABLE

[6] Pedro A. Ayuso. Pozos de nieve. Artículos literarios Alto Aragón No 84. Mayo de 2005 http://articulos.altoaragon.org/osca84.htm

[7] El Congreso pide que se impulse la cooperación institucional para finalizar obras de conducción de agua a Huesca, 29 (EUROPA PRESS). http://www. lukor.com/not-esp/ locales/ 0509/29181524.htm

[8] http://oph.chebro.es/DOCUMENTACION/DirectivaMarco/ResGranAbasEbro.pdf. Ministerio de Medio Ambiente y Medio Rural y Marino.

[9] www.cloro.info/index.asp?page=644. Asociación Nacional de Electroquímica.

[10] http://www.clearwater-tecnologia.com/es/agua_clorada.html. "Agua clorada: sinónimo de cáncer", artículo del Lic. Eduardo Omar Bonvissuto.

[11] Estación barranco de la Alfondida: se controla presión, nivel de cloro y turbidez en la red que proviene de Loporzano y en la que viene de Montearagón. Estación Depósito del Seminario: se controla presión en la red y nivel del depósito. Estación Depósito de Cola (Loma Cillas): presión en la red de entrada, nivel del depósito, nivel de cloro a la entrada y salida, control de válvulas. Estación Depósito SEPES: presiones en red de entrada y de salida, nivel de depósitos y control de válvulas.

[12] http://www.lukor.com/not-esp/locales/0509/29181524.htm. HUESCA, 29 (EUROPA PRESS. 